\title{
The In-vitro Antibacterial Effect of Colored Rice Crude Extracts against Staphylococcus aureus Associated with Skin and Soft-Tissue Infection
}

\author{
Pornpan Pumirat ${ }^{1} \&$ Natthanej Luplertlop ${ }^{1}$ \\ ${ }^{1}$ Department of Microbiology and Immunology, Faculty of Tropical Medicine, Mahidol University, Bangkok \\ 10400, Thailand \\ Correspondence: Natthanej Luplertlop, Department of Microbiology and Immunology, Faculty of Tropical \\ Medicine, Mahidol University, Bangkok 10400, Thailand. Tel: 66-2-354-9100. E-mail: \\ natthanej.lup@mahidol.ac.th
}

Received: July 18, 2013 Accepted: August 21, 2013 Online Published: October 15, 2013

doi:10.5539/jas.v5n11p102 URL: http://dx.doi.org/10.5539/jas.v5n11p102

\begin{abstract}
Due to increases in the resistance of bacteria to the existing antimicrobial agents, plants are being used as alternative sources for the development of safe, effective, and inexpensive new agents to treat and prevent bacterial infections. Recent studies have shown that rice (Oryza sativa L.), an important source of nutrients, consumed by most of the world's population, can suppress some bacterial infections. There are many varieties of rice, e.g. white, brown, black, and red; however, the relationship between rice color and antibacterial properties remains unclear. In the present study, we investigated the antibacterial activity of colored-rice crude extracts from four different types of colored rice (Hom Nil, Neaw Dum, Mun Poo, and Sang Yod) against common bacteria causing skin and soft-tissue infections, such as Staphylococcus aureus, Streptococcus pyogenes, Enterococcus spp., Pseudomonas aeruginosa, and Escherichia coli. The results showed that all colored-rice crude extracts had antibacterial effects against $S$. aureus; and more notably, crude extracts of differently colored rice restricted diverse antibacterial activities. To our knowledge, this is the first report that provides a basic understanding of the antibacterial properties of colored rice against skin and wound pathogens. An understanding of these properties would be invaluable in the development of alternative, natural, and safe methods of controlling bacterial infections.
\end{abstract}

Keywords: Oryza sativa L., colored rice, antibacterial effect, skin and soft tissue infections

\section{Introduction}

Bacterial skin and soft tissue infections (SSTIs) are some of the most common infections that can occur throughout the human life span (Compton, 2013; Ki \& Rotstein, 2008; Sarlangue, Boralevi, Barba, \& Leaute-Labreze, 2001). The clinical manifestations of SSTI range from simple uncomplicated superficial/cutaneous skin infections, such as cellulitis, erysipelas, impetigo, abscess, and wound infections, to life-threatening conditions, such as necrotizing fasciitis (flesh-eating bacteria) (Ki \& Rotstein, 2008; Tognetti et al., 2012). Bacterial SSTIs can be caused by both Gram-positive and Gram-negative organisms (Doern, Jones, Pfaller, Kugler, \& Beach, 1999; Khokhlova, Karelin, Belotserkovskii, \& Stetsiuk, 2011), with the most common causative agents being Gram-positive Staphylococcus aureus, Streptococcus pyogenes and Enterococcus species. SSTIs are also caused by a variety of Gram-negative bacteria, including Pseudomonas aeruginosa and Escherichia coli. Most infections are self-limited, but some complicated conditions require antibiotic treatment and/or hospitalization. In recent years, these infections have become more difficult to treat, as pathogens have developed resistance to many different types of antibiotics (Jones et al., 2004; Liu, 1999). While drugs to treat bacterial SSTIs are being investigated developed and tested, documented cases of treatment failure and adverse side effects (Sacchidanand et al., 2005; Scheinfeld, 2005; Upadya \& Ruxana, 2009) have added urgency to the development of new prevention and treatment modalities.

There is growing interest in plant-derived substances as alternative antimicrobial agents for the prophylaxis and treatment of disease (Mahady, 2005; Martin \& Ernst, 2003). The advantage of using plant medicine is that it is a natural product, and normally safer than synthetic or chemical compounds. Rice (Oryza sativa L.) is one of the most common plant products consumed by humans. It is grown worldwide and in some countries is part of almost every meal. It is known that rice harbors numerous nutrients that are good for health, and has shown potential 
antibacterial activity. For example, it has been reported that rice extract can inactivate some pathogenic enteric bacteria, such as Helicobacter pylori (Murakami et al., 2005) and Salmonella enterica serovar Typhimurium (Kim, Kang, Park, Nam, \& Friedman, 2012). There are many different varieties of rice; the most popular is white, but some rice varieties do possess other colors, e.g. brown, red, and black. Little is known about the extraordinary properties of colored rice; therefore, this study aimed to investigate the antibacterial effects of different types of colored-rice crude extract against common bacteria that cause skin and soft tissue infections.

\section{Materials and Methods}

\subsection{Bacterial Strains and Growth Conditions}

All of the bacteria used in this study were kindly provided by the Department of Microbiology and Immunology, Faculty of Tropical Medicine, Mahidol University, Thailand. S. aureus ATCC 25923, P. aeruginosa ATCC 27853, and E. coli ATCC 25922 were used as control strains. The clinical isolates of methicillin-sensitive $S$. aureus (MSSA, no.1-no.8), methicillin-resistant S. aureus (MRSA, no.9-no.10), S. pyogenes (no.11-no.15), Enterococcus spp. (no.16-no.20), P. aeruginosa (no.21-no.25) as well as E. coli (no.25-no.30) were included in the experimental study, which were independently isolated from infected skin and wound areas.

Bacteria were typically cultured in Luria-Bertani (LB) medium and grown at $37^{\circ} \mathrm{C}$ with or without shaking for 18-24 h.

\subsection{Preparation of Rice Extracts}

Four kinds of colored rice were obtained from farmers in Chiang Rai Province, Thailand: black non-waxy rice (local name Hom Nil; HN), black glutinous rice (local name Neaw Dum; ND), red rice (local name Mun Poo; MP), and brown rice (local name Sang Yod; SY). The crude extraction process was performed according to the Official Methods of Analysis of the Association of Official Analytical Chemistry (AOAC, 1995) with some modifications. Briefly, one hundred grams of each grain sample was processed by eliminating lipid interference components with $\mathrm{n}$-hexane $(500 \mathrm{ml})$, followed by Soxhlet extraction with ethanol absolute (Merck) for $6 \mathrm{~h}$ at a condensation rate of 2-3 drops/sec. The prepared crude extract was then evaporated in an evaporator to remove the solvent. Dry crude extract was resuspended with sterile LB medium and stored at $-20^{\circ} \mathrm{C}$ for analysis.

\subsection{Antibacterial Susceptibility Testing}

To determine the susceptibility of bacteria to rice crude extract, Bauer-Kirby paper disc diffusion/inhibition testing, with some modifications, was used. Each bacterial strain culture had been adjusted to $10^{8}$ colony-forming units $(\mathrm{CFU}) / \mathrm{ml}$ by measuring optical density (OD) at a wavelength of $600 \mathrm{~nm}$ to $0.1 .100 \mu$ of prepared bacterial culture were spread onto a $20 \mathrm{ml}$ Mueller-Hinton (MH) agar plate and left for 5 minutes to dry. Meanwhile, an aliquot of $10 \mu \mathrm{l}$ of $1 \mathrm{mg} / \mathrm{ml}$ of each crude extract was individually applied to sterile filter-paper discs (Whatman no. 1; $6 \mathrm{~mm}$ in diameter). Then, the paper discs with $10 \mu \mathrm{g}$ of rice crude extract were placed onto a bacteria-inoculated $\mathrm{MH}$ agar plate and incubated at $37^{\circ} \mathrm{C}$. For reagent control testing, the paper disc contained LB medium was also included to show that it did not involve with antibacterial effect. Antibacterial activity was evaluated by measuring the diameter of the zone of growth inhibition around the disc after $24 \mathrm{~h}$ incubation.

\subsection{Determination of Minimum Inhibitory Concentration (MIC) and Minimum Bactericidal Concentration (MBC)}

A modified Clinical and Laboratory Standard Institute broth-microdilution method (CLSI, 2009b) was used to obtain the MIC and MBC of the rice crude extracts. Two-fold serial dilutions of each extract were processed to obtain concentrations ranging from 125 to $1000 \mu \mathrm{g} / \mathrm{ml}$. The bacterial inoculums $(100 \mu \mathrm{l})$ containing $10^{8} \mathrm{CFU} / \mathrm{ml}$ were added to each well. A positive control with $1 \%$ DMSO and a negative control without an added inoculum were included. The microliter plates were then incubated at $37^{\circ} \mathrm{C}$ for $18 \mathrm{~h}$. The MIC values were recorded in duplicate as the lowest concentration of rice crude extract that completely inhibited bacterial growth. Minimum bactericidal concentrations were assessed using a selected concentration of crude rice extract that gave significant MIC values and sub-culturing on fresh MH agar. No colony growth was observed.

\subsection{Assessment of Bacterial Survival}

Bacterial survival in the presence of rice crude extracts was noted. In summary, an overnight culture of bacteria was adjusted to $\mathrm{OD}_{600} 0.5$ and inoculated at a ratio of 1:500 into standard LB broth with or without additional rice crude extract (to reach a final concentration of $0.5 \mathrm{mg} / \mathrm{ml}$ ). Every $4 \mathrm{~h}$ after inoculation, the cultures were serially diluted for plating and incubated at $37^{\circ} \mathrm{C}$ for $18-24 \mathrm{~h}$. Bacterial survival was evaluated by counting the CFU. Percent bacterial survival was determined using the formula:

$$
\% \text { Survival }=\left[\mathrm{CFU}_{(\text {with rice extract })} / \mathrm{CFU}_{(\text {without rice extract })}\right] \times 100
$$

Thus, the bacterial condition without the addition of crude rice extract represented $100 \%$ survival. 


\subsection{Statistical Analysis}

All assays were conducted in triplicate and Student's $t$-tests of independent experiments were performed using PASW Statistics 18 software. Differences were considered significant for p value $<0.05(*),<0.01(* *)$ and $<$ $0.001(* * *)$.

\section{Results and Discussion}

We evaluated the potential antibacterial activity of rice crude extracts from four different types of colored rice (HN, ND, MP and SY) against pathogenic bacteria-causing SSTIs. The antibacterial effects of colored-rice crude extract on control strains of three skin and wound bacteria (S. aureus ATCC 25923, P. aeruginosa ATCC 27853, and E. coli ATCC 25922) are shown in Figure 1. Among the control groups, all four colored-rice crude extracts produced significant zones of inhibition only against $S$. aureus ATCC 25923, with no zone of inhibition against $P$. aeruginosa ATCC 27853 or E. coli ATCC 25922. The average values of the inhibition zones for the colored-rice crude extracts are shown in Table 1 . The results show antibacterial activity against $S$. aureus ATCC 25923 of the colored-rice crude extracts using the disc diffusion assay, with inhibition zones ranging from 7 to $13 \mathrm{~mm}$. The HN crude extract exhibited the strongest antibacterial effect against $S$. aureus ATCC 25923. The MIC and MBC values of the colored-rice crude extracts against the control organisms were also examined. The MICs of the colored-rice crude extracts for S. aureus ATCC 25923 were $125 \mu \mathrm{g} / \mathrm{ml}$ for HR, and $250 \mu \mathrm{g} / \mathrm{ml}$ for MP, ND, and SY (Table 2). All colored-rice crude extracts showed anti-staphylococcal action with MBC values at concentrations of $500 \mu \mathrm{g} / \mathrm{ml}$ (Table 2). On the other hand, none of the four colored-rice crude extracts inhibited the growth of $P$. aeruginosa and E. coli at any concentration (Table 2). This is the first report of colored-rice extract having an inhibitory effect on $S$. aureus.
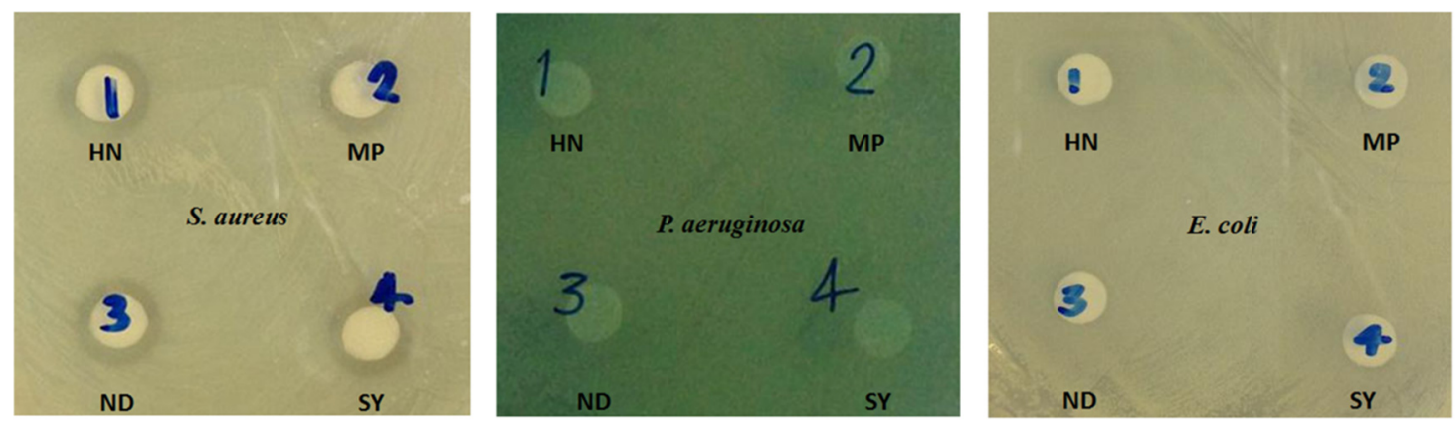

Figure 1. Antibacterial activity of four colored-rice extracts against control strains of $S$. aureus ATCC 25923, $P$. aeruginosa ATCC 27853, and E. coli ATCC 25922, by filter disc diffusion method. Filter-paper disc, $6 \mathrm{~mm}$ in diameter

Table 1. Inhibition zones of four colored-rice extracts against control strains of $S$. aureus ATCC 25923, P. aeruginosa ATCC 27853, and E. coli ATCC 25922 by filter disc diffusion method

\begin{tabular}{lcccc}
\hline \multirow{2}{*}{ Bacteria } & \multicolumn{4}{c}{ Inhibitory zone (mm) } \\
\cline { 2 - 5 } & $\mathrm{HN}$ & $\mathrm{MP}$ & $\mathrm{ND}$ & $\mathrm{SY}$ \\
\hline S. aureus & $9.4 \pm 0.5$ & $8.2 \pm 0.5$ & $8.5 \pm 0.4$ & $8.6 \pm 0.4$ \\
P. aeruginosa & $\mathrm{NZ}$ & $\mathrm{NZ}$ & $\mathrm{NZ}$ & $\mathrm{NZ}$ \\
E. coli & $\mathrm{NZ}$ & $\mathrm{NZ}$ & $\mathrm{NZ}$ & $\mathrm{NZ}$ \\
\hline
\end{tabular}

Disc size $=6 \mathrm{~mm} ; \mathrm{NZ}=$ No inhibition zone. 
Table 2. MIC and MBC of four colored-rice extracts against control strains of S. aureus ATCC 25923, P. aeruginosa ATCC 27853, and E. coli ATCC 25922

\begin{tabular}{lccccc}
\hline \multirow{2}{*}{ Bacteria } & \multicolumn{4}{c}{ MIC/MBC $(\mu \mathrm{g} / \mathrm{ml})$} \\
\cline { 2 - 5 } & HN & MP & ND & SY \\
\hline S. aureus & $125 / 500$ & $250 / 500$ & $250 / 500$ & $250 / 500$ \\
P. aeruginosa & NA & NA & NA & NA \\
E. coli & NA & NA & NA & NA \\
\hline
\end{tabular}

NA $=$ Not applicable

We also analyzed percentage survival of $S$. aureus ATCC 25923 post-exposure to $500 \mu \mathrm{g} / \mathrm{ml}$ of rice crude extract. Figure 2 shows that, with all colored-rice crude extracts, bacteria survival reduced. Percent survival after colored-rice crude extract treatment reduced significantly, albeit gradually, over time ( $\mathrm{p}$ value $\leq 0.01$ ). About $50 \%$ died at $8 \mathrm{~h}$ post-exposure to colored-rice crude extract. Among the four extracts, HN exhibited antibacterial activity with the greatest reduction in $S$. aureus survival. In contrast, MP exhibited antibacterial activity with the smallest reduction in S. aureus survival. However, ND and SY showed similar declines in antibacterial activity against $S$. aureus. These results indicated that different colored-rice extracts have different levels of antibacterial activity.

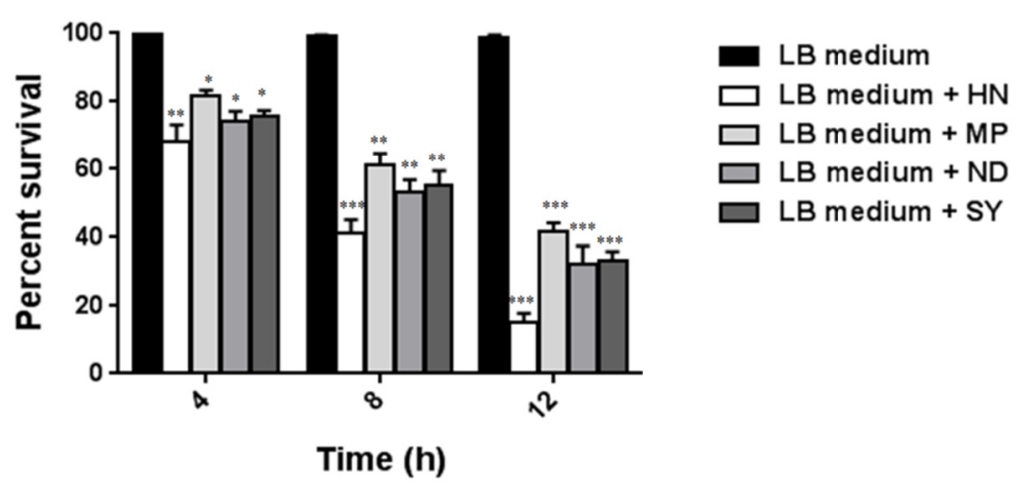

Figure 2. Evaluation of S. aureus survival in the presence of colored-rice extracts. Overnight culture of S. aureus ATCC 25923 was inoculated in five differential media (LB broth with or without $500 \mu \mathrm{g} / \mathrm{ml}$ colored-rice extracts) and maintained at $37^{\circ} \mathrm{C}$. Their viable colony-forming units (CFU) were counted before and after 4,8 , and $12 \mathrm{~h}$ of treatment with colored-rice extract and calculated for percent survival, as explained in the Materials and Methods section. Data shown are averages from three experiments. Asterisks indicate significant differences between the LB-broth, and LB broth with $500 \mu \mathrm{g} / \mathrm{ml}$ colored-rice extract, groups. * represents $\mathrm{p}$ value $<0.05$, ${ }^{* *}$ represents $\mathrm{p}$ value $<0.01$ and $* * *$ represents $\mathrm{p}$ value $<0.001$

Colored-rice crude extracts were further investigated against a panel of clinically isolated skin and wound bacteria (MSSA, MRSA, S. pyogenes, Enterococcus spp., P. aeruginosa, and E. coli). Table 3 shows the sensitivity of MSSA- and MRSA- clinical isolates to all four extracts, with inhibition zones ranging from 7 to $11 \mathrm{~mm}$. As expected, HN extract showed the greatest inhibitory activity against both strains of clinical S. aureus, like control strain ATCC 25923. Moreover, all colored-rice extracts showed MIC and MBC against clinically isolated $S$. aureus at concentrations of $125-500 \mu \mathrm{g} / \mathrm{ml}$ and $500-1000 \mu \mathrm{g} / \mathrm{ml}$, respectively (Table 4). Conversely, clinical isolates of $S$. pyogenes, Enterococcus spp., P. aeruginosa and E. coli were resistant to all colored-rice crude extracts, as observed with control strains of $P$. aeruginosa ATCC 27853 and E. coli ATCC 25922. Taken together, there was better activity against $S$. aureus than other bacteria, indicating colored-rice extracts had specificity for antibacterial activity. 
Table 3. Inhibition zones of four colored-rice extracts against clinical isolates of $S$. aureus, S. pyogenes, Enterococcus spp., P. aeruginosa, and E. coli, by filter disc diffusion method

\begin{tabular}{cccccc}
\hline Clinical isolate & \multicolumn{5}{c}{ Inhibitory zone (mm) } \\
\cline { 2 - 6 } Bacteria & No. & HN & MP & ND & SY \\
\hline S. aureus & 1 & $9.4 \pm 0.3$ & $8.3 \pm 0.5$ & $8.5 \pm 0.4$ & $8.6 \pm 0.4$ \\
& 2 & $9.1 \pm 0.5$ & $8.2 \pm 0.7$ & $8.6 \pm 0.5$ & $8.5 \pm 0.3$ \\
& 3 & $9.2 \pm 0.2$ & $8.2 \pm 0.4$ & $8.4 \pm 0.3$ & $8.5 \pm 0.3$ \\
& 4 & $8.7 \pm 0.4$ & $7.8 \pm 0.3$ & $8.2 \pm 0.2$ & $8.2 \pm 0.4$ \\
& 5 & $8.9 \pm 0.2$ & $8.2 \pm 0.3$ & $8.3 \pm 0.4$ & $8.4 \pm 0.2$ \\
& 6 & $9.0 \pm 0.4$ & $8.2 \pm 0.5$ & $8.4 \pm 0.5$ & $8.4 \pm 0.5$ \\
& 7 & $8.8 \pm 0.5$ & $8.2 \pm 0.4$ & $8.2 \pm 0.4$ & $8.2 \pm 0.4$ \\
& 8 & $8.6 \pm 0.5$ & $7.9 \pm 0.4$ & $8.2 \pm 0.4$ & $8.3 \pm 0.4$ \\
S. pyogenes & $11-15$ & $\mathrm{NZ}$ & $\mathrm{NZ}$ & $\mathrm{NZ}$ & $\mathrm{NZ}$ \\
Enterococcus spp. & $16-20$ & $\mathrm{NZ}$ & $\mathrm{NZ}$ & $\mathrm{NZ}$ & $\mathrm{NZ}$ \\
P. aeruginosa & $21-25$ & $\mathrm{NZ}$ & $\mathrm{NZ}$ & $\mathrm{NZ}$ & $\mathrm{NZ}$ \\
E. coli & $26-30$ & $\mathrm{NZ}$ & $\mathrm{NZ}$ & $\mathrm{NZ}$ & $\mathrm{NZ}$ \\
\hline
\end{tabular}

Disc size $=6 \mathrm{~mm} ; \mathrm{NZ}=$ No inhibition zone.

Table 4. MIC and MBC of four colored-rice extracts against clinical isolates of S. aureus, S. pyogenes, Enterococcus spp., P. aeruginosa, and E. coli

\begin{tabular}{|c|c|c|c|c|c|}
\hline \multicolumn{2}{|l|}{ Clinical isolate } & \multicolumn{4}{|c|}{$\mathrm{MIC} / \mathrm{MBC}(\mu \mathrm{g} / \mathrm{ml})$} \\
\hline Bacteria & No. & $\mathrm{HN}$ & MP & ND & SY \\
\hline S. aureus & 1 & $250 / 500$ & $250 / 500$ & $250 / 500$ & $250 / 500$ \\
\hline & 2 & $125 / 500$ & $250 / 500$ & $250 / 500$ & $250 / 500$ \\
\hline & 3 & $250 / 500$ & $250 / 500$ & $250 / 500$ & $250 / 500$ \\
\hline & 4 & $500 / 500$ & $500 / 500$ & $500 / 500$ & $500 / 500$ \\
\hline & 5 & $250 / 1,000$ & $500 / 1,000$ & $500 / 1,000$ & $500 / 1,000$ \\
\hline & 6 & $250 / 500$ & $250 / 500$ & $250 / 500$ & $250 / 500$ \\
\hline & 7 & $250 / 500$ & $250 / 500$ & $250 / 500$ & $250 / 500$ \\
\hline & 8 & $250 / 500$ & $250 / 500$ & $250 / 500$ & $250 / 500$ \\
\hline & 9 & $500 / 1,000$ & $500 / 1,000$ & $500 / 1,000$ & $500 / 1,000$ \\
\hline & 10 & $500 / 1,000$ & $500 / 1,000$ & $500 / 1,000$ & $500 / 1,000$ \\
\hline S. pyogenes & $11-15$ & NA & NA & NA & NA \\
\hline Enterococcus spp. & $16-20$ & NA & NA & NA & NA \\
\hline P. aeruginosa & $21-25$ & NA & NA & NA & NA \\
\hline E. coli & $26-30$ & NA & NA & NA & NA \\
\hline
\end{tabular}

$\mathrm{NA}=$ Not applicable.

With the increase in resistance to many existing antibacterial agents (Doern, et al., 1999; Jones, et al., 2004; Liu, 1999), especially in the treatment of skin diseases, there is a good opportunity to develop new treatments using plants or plant-based formulas. Many plants are already commonly used in several countries to treat or prevent SSTIs (Dholvitayakhun, Cushnie, \& Trachoo, 2012; Mahady, 2005; Olugbuyiro, Abo, \& Leigh, 2010; 
Trakulsomboon, Kummalue, \& Jiratchariyakul, 2006). Nevertheless, limited data currently exist to prove their efficacy against SSTI-related pathogens. Rice (Oryza sativa L.) has recently become an interesting candidate as a natural antibacterial agent. It has been reported that rice extract is effective in suppressing damage to the gastric mucosa in H. pylori-infected Mongolian gerbils (Murakami, et al., 2005). Moreover, rice-hull-smoke extract has been shown to inhibit $S$. enterica serovar Typhimurium in vitro, and protected infected mice from death (Kim, et al., 2012). This study has substantiated the antibacterial property of colored-rice extracts, in particular against skin and wound pathogenic $S$. aureus. The antibacterial activity of colored-rice extracts was examined using several reliable techniques. It has been noted that Bauer-Kirby disk susceptibility-, MIC- and MBC-based determination are widely used for investigating the antimicrobial susceptibility of various bacteria (Gonzalez et al., 2013; Liberman \& Robertson, 1975; Traub, Spohr, \& Bauer, 1987; Van Asselt \& Van Boven, 1997).

Colored rice varieties-mainly black, red, and purple-contain a variety of bioactive constituents, i.e. flavones, anthocyanins, tannin, phenolics, sterols, tocols, $\gamma$-oryzanols, amino acids, and essential oils (Chakuton, Puangpronpitag, \& Nakornriab, 2012; Deng et al., 2013). Several phenolic compounds of colored-rice have been reported on the antioxidant and anti-inflammatory properties, both in vitro and in vivo (Fujita, Fujitake, Kawakami, \& Nomura, 2010; Muntana \& Prasong, 2010; Toyokuni et al., 2002). However, the antimicrobial effect of colored rice has not been reported before. Presently, our study results strongly suggested that colored-rice crude extracts exhibited anti-staphylococcal activity. However, larger sample sizes and other varieties of SSTI-causing bacteria, as well as a wider range of colored-rice varieties are required for further investigation, to provide a better understanding of specific inhibition. Although colored-rice crude extracts may not affect some bacteria, such as $S$. pyogenes, Enterococcus spp., P. aeruginosa and E. coli; they could be used to develop medical formulas in combination with other antibacterial agents with proven effect on these bacteria.

\section{Conclusion}

Our findings exhibited a basis for future applications of colored-rice crude extracts, which may provide advantages in skin treatment or protection against bacterial infections. For example; incorporating colored-rice crude extracts into medicines and/or skin-care products, such as soaps, creams, and lotions, to protect the skin from bacterial infections. However, further intensive research in animals and humans is required, to verify the safety, efficacy, and mechanism of action of colored-rice extracts in the prevention and treatment of infections caused by bacterial pathogens.

\section{Acknowledgements}

We acknowledge the Department of Microbiology and Immunology, Faculty of Tropical Medicine, Mahidol University for providing the clinical samples used in this study. We thank Mr. Paul Adams and the Office of Research Services, Faculty of Tropical Medicine, Mahidol University, for proof-reading the manuscript, and Mr. Witawat Tunyong for assistance preparing bacteria.

\section{References}

AOAC. (1995). Official Methods of Analysis of the Association of Official Analytical Chemistry (16th ed.): Association of Official Analytical Chemists, Washington, DC.

Chakuton, K., Puangpronpitag, D., \& Nakornriab, M. (2012). Phytochemical content and antioxidant activity of colored and non-colored Thai rice cultivars. Asian Journal of Plant Sciences, 11, 285-293. http://dx.doi.org/10.3923/ajps.2012.285.293

Compton, G. A. (2013). Bacterial skin and soft tissue infections in older adults. Clin Geriatr Med, 29(2), 443-459. http://dx.doi.org/10.1016/j.cger.2013.01.002/S0749-0690(13)00003-7

Deng, G. F., Xu, X. R., Zhang, Y., Li, D., Gan, R. Y., \& Li, H. B. (2013). Phenolic compounds and bioactivities of pigmented rice. Crit Rev Food Sci Nutr, 53(3), 296-306. http://dx.doi.org/10.1080/10408398.2010.529624

Dholvitayakhun, A., Cushnie, T. P., \& Trachoo, N. (2012). Antibacterial activity of three medicinal Thai plants against Campylobacter jejuni and other foodborne pathogens. Nat Prod Res, 26(4), 356-363. http://dx.doi.org/10.1080/14786419.2010.545777

Doern, G. V., Jones, R. N., Pfaller, M. A., Kugler, K. C., \& Beach, M. L. (1999). Bacterial pathogens isolated from patients with skin and soft tissue infections: frequency of occurrence and antimicrobial susceptibility patterns from the SENTRY Antimicrobial Surveillance Program (United States and Canada, 1997). SENTRY Study Group (North America). Diagn Microbiol Infect Dis, 34(1), 65-72. http://dx.doi.org/S073288939800162X

Fujita, A., Fujitake, H., Kawakami, K., \& Nomura, M. (2010). Antioxidant activity of colored rice bran obtained at different milling yields. J Oleo Sci, 59(10), 563-568. http://dx.doi.org/JST.JSTAGE/jos/59.563 
Gonzalez, N., Sevillano, D., Alou, L., Cafini, F., Gimenez, M. J., Gomez-Lus, M. L., ... Aguilar, L. (2013). Influence of the $\mathrm{MBC} / \mathrm{MIC}$ ratio on the antibacterial activity of vancomycin versus linezolid against methicillin-resistant Staphylococcus aureus isolates in a pharmacodynamic model simulating serum and soft tissue interstitial fluid concentrations reported in diabetic patients. $J$ Antimicrob Chemother. http://dx.doi.org/dkt185/10.1093/jac/dkt185

Jones, M. E., Karlowsky, J. A., Draghi, D. C., Thornsberry, C., Sahm, D. F., \& Bradley, J. S. (2004). Rates of antimicrobial resistance among common bacterial pathogens causing respiratory, blood, urine, and skin and soft tissue infections in pediatric patients. Eur $J$ Clin Microbiol Infect Dis, 23(6), 445-455. http://dx.doi.org/10.1007/s10096-004-1133-5

Khokhlova, V. N., Karelin, A. A., Belotserkovskii, M. V., \& Stetsiuk, O. U. (2011). Analysis of the spectrum of bacterial pathogens isolated from patients with complicated skin and soft tissue infections presumably due to grampositive or mixed flora in the countries of the Central and East Europe. Antibiot Khimioter, 56(5-6), 19-29.

Ki, V., \& Rotstein, C. (2008). Bacterial skin and soft tissue infections in adults: A review of their epidemiology, pathogenesis, diagnosis, treatment and site of care. Can J Infect Dis Med Microbiol, 19(2), 173-184.

Kim, S. P., Kang, M. Y., Park, J. C., Nam, S. H., \& Friedman, M. (2012). Rice hull smoke extract inactivates Salmonella Typhimurium in laboratory media and protects infected mice against mortality. J Food Sci, 77(1), M80-85. http://dx.doi.org/10.1111/j.1750-3841.2011.02478.x

Liberman, D. F., \& Robertson, R. G. (1975). Evaluation of a rapid Bauer-Kirby antibiotic susceptibility determination. Antimicrob Agents Chemother, 7(3), 250-255.

Liu, H. H. (1999). Antibiotic resistance in bacteria. A current and future problem. Adv Exp Med Biol, 455, 387-396.

Mahady, G. B. (2005). Medicinal plants for the prevention and treatment of bacterial infections. Curr Pharm Des, $11(19), 2405-2427$.

Martin, K. W., \& Ernst, E. (2003). Herbal medicines for treatment of bacterial infections: a review of controlled clinical trials. J Antimicrob Chemother, 51(2), 241-246.

Muntana, N., \& Prasong, S. (2010). Study on total phenolic contents and their antioxidant activities of Thai white, red and black rice bran extracts. PakJ Biol Sci, 13(4), 170-174.

Murakami, M., Ota, H., Sugiyama, A., Ishizone, S., Maruta, F., Akita, N., ... Tokuyama, T. (2005). Suppressive effect of rice extract on Helicobacter pylori infection in a Mongolian gerbil model. J Gastroenterol, 40(5), 459-466. http://dx.doi.org/10.1007/s00535-005-1570-7

Olugbuyiro, J. A., Abo, K. A., \& Leigh, O. O. (2010). Wound healing effect of Flabellaria paniculata leaf extracts. J Ethnopharmacol, 127(3), 786-788. http://dx.doi.org/10.1016/j.jep.2009.10.008/S0378-8741(09)00649-7

Sacchidanand, S., Penn, R. L., Embil, J. M., Campos, M. E., Curcio, D., Ellis-Grosse, E., ... Rose, G. (2005). Efficacy and safety of tigecycline monotherapy compared with vancomycin plus aztreonam in patients with complicated skin and skin structure infections: Results from a phase 3, randomized, double-blind trial. Int $J$ Infect Dis, 9(5), 251-261. http://dx.doi.org/S1201-9712(05)00098-6/10.1016/j.ijid.2005.05.003

Sarlangue, J., Boralevi, F., Barba, G., \& Leaute-Labreze, C. (2001). Skin and soft tissue bacterial infections in newborns. Arch Pediatr, 8 Suppl 2, 462s-464s.

Scheinfeld, N. (2005). Tigecycline: a review of a new glycylcycline antibiotic. J Dermatolog Treat, 16(4), 207-212. http://dx.doi.org/H337H3321H227535/10.1080/09546630510011810

Tognetti, L., Martinelli, C., Berti, S., Hercogova, J., Lotti, T., Leoncini, F., \& Moretti, S. (2012). Bacterial skin and soft tissue infections: review of the epidemiology, microbiology, aetiopathogenesis and treatment: a collaboration between dermatologists and infectivologists. J Eur Acad Dermatol Venereol, 26(8), 931-941. http://dx.doi.org/10.1111/j.1468-3083.2011.04416.x

Toyokuni, S., Itani, T., Morimitsu, Y., Okada, K., Ozeki, M., Kondo, S., .. Tashiro, T. (2002). Protective effect of colored rice over white rice on Fenton reaction-based renal lipid peroxidation in rats. Free Radic Res, 36(5), 583-592.

Trakulsomboon, S., Kummalue, T., \& Jiratchariyakul, W. (2006). Antibacterial activities of four Thai medicinal plants. J Med Assoc Thai, 89(9), 1466-1471. 
Traub, W. H., Spohr, M., \& Bauer, D. (1987). Tentative inhibition zone criteria (Bauer-Kirby agar disk diffusion method) for rifampin against Staphylococci. Chemotherapy, 33(6), 412-418.

Upadya, G. M., \& Ruxana, K. (2009). Toxic epidermal necrolysis and agranulocytosis: rare adverse effects of ciprofloxacin. Indian $J$ Med Sci, 63(10), 461-463. http://dx.doi.org/10.4103/0019-5359.57648 IndianJMedSci_2009_63_10_461_57648

Van Asselt, G. J., \& Van Boven, C. P. (1997). Guidelines for detection of penicillin tolerance in Streptococcus pyogenes by MIC-MBC method. Adv Exp Med Biol, 418, 451-452.

\section{Copyrights}

Copyright for this article is retained by the author(s), with first publication rights granted to the journal.

This is an open-access article distributed under the terms and conditions of the Creative Commons Attribution license (http://creativecommons.org/licenses/by/3.0/). 